\title{
Gestos imperceptíveis: cidades em (des) ocupações... (des)territorializações...
}

\section{Des gestes imperceptibles: des villes en (dis)occupations et dé- territorialisations}

https://doi.org/10.34112/2317-0972a2017V35n69p37-55

Elenise Cristina Pires de Andrade ${ }^{1}$

Louise Mara SoAREs Bastos ${ }^{2}$

ResUmO: Expressões de cidades em experimentação através de imagens a nos auxiliar a responder as seguintes questões que essa escritapesquisa lança: o que podem as imagens quando não pretendem explicar, ilustrar, registrar as cidades? Ocupações (im)prováveis? Desterritorializações (im)possíveis? Dois momentos de produção de imagens que (se) pretendem des...: um evento de grafite em um distrito de Feira de Santana, BA - Bonfim da Feira - e oficinas de fotografias em Ichu, no sertão baiano, realizadas com alunos do ensino médio de uma escola pública. Grafites-muros, ruas-diagramas a desorganizarem o senso comum, a implodirem uma busca estrita da recognição, fissuras na política de pensar o já pensado. Outras (des)ordens, linhas de potência em gestos imperceptíveis. Re-a-linhar o pensar a sensação para o plano educação, desconsiderando movimentos que levem a concretizações, centralidades e determinações seja da ciência, da arte, do tempo, da produção de conhecimento ou do próprio pensamento. Outros modos de existência em (des)ocupações...

Palavras-chave: Cidade; filosofia da diferença; imagens.

ABSTRAIT: Expressions des villes dans l'expérimentation à travers les images pour nous aider à répondre aux questions suivantes que cette écriturerecherche nous pose: qu'est-ce que les

1. Universidade Estadual de Feira de Santana, Feira de Santana, BA, Brasil.

2. Universidade Estadual de Feira de Santana, Feira de Santana, BA, Brasil. 
Gestos imperceptíveis: cidades em (des)ocupações... (des)territorializações...

images peuvent faire quand elles ne veulent pas expliquer, illustrer, enregistrer les villes? Les prendre? Les quitter? Dé-territorialisations (im)possible? Deux moments de production d'image avec l'intention des ...: un événement des graffiti dans un quartier de Feira de Santana, BA - Bonfim da Feira - et des ateliers de photographie à Ichu, dans les régions arides de Bahia, réalisés avec les lycéens d'une école publique. Graffiti-murs, des rues, des diagrames, de la pensée avec Deleuze, qui perturbent les sens commun et implosent une recherche stricte de la reconnaissance, des fissures dans la pensée politique du déjà pensé. Autres (dés) ordre, les lignes des puissance, gestes imperceptibles. A-ligner le penser de sensation pour le plan de l'éducation, sans tenir compte des mouvements qui conduisent à des formes de concrétion, centralités et déterminations qui ce soit sur l'art, le temps, la production de connaissances ou de la pensée elle-même. D'autres modes d'existence dans (dis) occupations ... MotS-CLÉS: Ville; philosophie de la différence; images.

GESTOS: Movimento expressivo de ideias.

(Dicionário Aurélio online) ${ }^{3}$

KLEXOS: Talvez devêssemos pensar na própria memória como uma obra de arte - e uma obra de arte nunca é terminada, apenas abandonada.

(Dicionário das Tristezas Obscuras) $^{4}$

AMBEDO: Um tipo de transe melancólico no qual você se torna completamente absorto por pequenos detalhes sensoriais - pingos de chuva escorrendo pela janela, árvores altas se dobrando lentamente com o vento, espirais de creme se formando no café - o que, por fim, leva a uma avassaladora constatação da fragilidade da vida. (Dicionário das Tristezas Obscuras) $^{5}$

\section{Gestos...}

Expressões, arte, pequenos detalhes sensoriais, reticências convidando a partícula des. Expressões de cidades em experimentação através de imagens nos propondo algumas tensões para as seguintes questões que essa escritapesquisa lança: o que podem as imagens quando não pretendem explicar, ilustrar, registrar as cidades?

3. Disponível em: <https://dicionariodoaurelio.com/gesto >. Acesso em: o1 dez. 2016.

4. Tradução nossa. Disponível em: <http://www.dictionaryofobscuresorrows.com/>. Acesso em: 07 fev. 2016.

5. Disponível em: <https://noosfera.com.br/o-dicionario-das-tristezas-obscuras/>. Acesso em: 07 fev. 2016. 
Ocupações (im)prováveis? Desterritorializações (im)possíveis? Grafites-muros, ruas-diagramas a desorganizarem o senso comum, a implodirem uma busca estrita da recognição, fissuras na política de pensar o já pensado.

A cidade, comumente, é entendida quase que estritamente em seu espaço físico, dividida, referenciada em nomes de ruas e avenidas, CEPs, localizações pelo Global Positioning System (GPS). Que globalidades emergem dessa cidade singular? Ferramentas como Google Maps e Google Earth parecem nos possibilitar ver os lugares de cima, dimensões do território, rotas de entrada e saída. Voos (im)possíveis que nos lançam a cores que se acumulam à medida que as linhas se tornam mais evidentes e acentuadas. Linhas-traços-diagramas. Zona que se habita em torno de um centro onde tudo se encontra, "unidade de totalização" (DELEUZE; GUATTARI, 1995, p. 14) de uma cidade: para onde correm as principais vias de acesso, aonde circulam a maioria das pessoas. (Des)ocupações dos silêncios, dos ruídos, dos murmúrios. Que muros são esses? As residências se distribuem em círculos, triângulos, a cidade cresce em torno de si mesma.

Telhados enfileirados, cheios de nomes e dados que dão lugar a carros, asfaltos, fachadas, cores, corpos. Uma cidade é feita de limites geográficos, cidades-círculos, cidades-triângulos, como parecem comprovar as imagens do Google Maps, mas cresce e se move em vida: o dentista da avenida tal, a costureira da rua qual, a escola é distante do centro, o mercado é perto de casa. Pernas que caminham, carros que se alinham, manequins que esperam, sorvete que passa, camisa que azuleja, prédio que faz sombra. Uma cidade cresce em ramificações diversas que desafiam a lógica estruturante de uma organização que a divide, nomeia, numera, especifica, localiza.

Provoc-ações. Ações que insistem na provocação dos hifens e parênteses nas (im)possibilidades de ensaiar por fragmentos. Fios-palavras em uma intimidade quase exposta. Gestos. Imagens que escorrem. Dois momentos de produção de imagens que (se) pretendem des...: um evento de grafite em um distrito de Feira de Santana, BA - Bonfim da Feira - e oficinas de fotografias em Ichu, no sertão baiano, realizadas com alunos do ensino médio de uma escola pública ${ }^{6}$.

Vontade de propor que a cidade não seja entendida, sentida, explorada apenas como cenário, mas sim que se desenhe máquina produtora de signos, expressão,

6. Esta última atividade decorrente do projeto de pesquisa: "Cidades (des)enquadradas em imagens: experimentações (atra)versando o conceito de signo”. Edital CNPq, 043/2013 Ciências Humanas, Sociais e Sociais Aplicadas, processo no. 409115/2013-4 (ANDRADE, 2013-2016). 
conhecimentos, “[...] outros modos de ver, de maquinar e de magicar" (GODINHO, 2016, p. 33). Potência dos fragmentos em gestos em devir.

Queremos, aqui, desafiar - des-afiar - a relação que parece ser 'intrínseca' de que o sentido acompanha uma explicação e, talvez até mais relevante, de que essa seria quase uma operação matemática cuja ordem dos fatores não alteraria o produto, ou seja, a explicação acompanharia o sentido! Cidades que escapam, se contorcem, desmoronam de uma representatividade. Por onde transita essa vontade de (sem) sentido com um entendimento objetivo em uma relação para esvaziar o plano 'educação' em (des)ocupação?

Grafitar, fotografar e pós produzir as imagens. Gestos potentes que, nesse texto, nos ajudam a pensar nos conceitos de signo, diagrama, re-des territorialização (acompanhando as movimentações de Deleuze e Deleuze e Guattari) junto à desestabilização de uma política da representação para olhar, sentir, explorar, inventar, conhecer cidades, ruas, escolas, vidas. Desestabilizar essa rostidade que quer se mostrar nos mapas como um rosto geométrico. Desmedir as potências da terra. "A máquina de rostidade vê e estabelece parâmetros, esquadrinha os sujeitos e os condiciona a ambientes predeterminados a partir de dados intangíveis" (CARVALHO; FERRAÇO, 2014, p. 147).

Esvaziar dados já dados de antemão. Desfazer os dualismos. Não perguntar o que esses gestos mostram da/na/com a cidade, mas o que as intensidades e forças que a atravessam e povoam querem nos mostrar... "Difícil é não haver um mundo à nossa espera para ser criado, é estar no meio" (GODINHO, 2016, p. 33). Deslocar, desclassificar, des-narrar, pensamentos desejantes em desequilibrar fronteiras fixas entre imagem, ficção e realidade; conhecimento e explicação; educação, arte e criação, indo em busca de um modo, um funcionamento do gesto. Intensidade do instante.

Propomo-nos: pensar com potências que nunca são más nem negativas, com forças novas e desconhecidas, forças sem palavras e, com elas, sem imagens e com milhões de imagens a passar sem cessar, sempre com sons e gritos não sonoros, sensações e afectos alegres que penetram de forma assignificante todos os corpos. (GODINHO, 2016, p. 34).

$\operatorname{Des}(. .$.$) o campo educação.$ 
KLEXOS

Infinidades de linhas, traçar de fios em tempos desvairados. Tempos ondulados, tempos entre ondas conectados. Ali a expressão é resto daquilo que escapa. Trazer à presença a escapada, povoar de superfícies inapreensiveis.

Escrita que se chove ondas, que se inunda superfícies de vida. Crianças que brincam, que esqueceram os nomes e os pronomes. Verbos molhados e com fome: chorar, viver, passar, ondular, durar...

Sebastian Wiedemann, 2016.

A cidade se articula em linhas, não do tipo que circulam, mas que entram e saem por todos os lugares, "passa entre as coisas, entre os pontos" (DELEUZE; GUATTARI, 1997, p. 220), segmentos que territorializam, organizam, significam, referenciam, mas também em linhas que querem fugir, "linhas de desterritorialização pelas quais [...] foge sem parar” (DELEUZE; GUATTARI, 1995, p. 18). É possível traçar para si uma linha de fuga? Arrastá-las para um lugar distante, criar para si um outro lugar, "uma nova terra, um universo, e já não só uma reterritorialização" (DELEUZE; GUATTARI, 1997, p. 225).

Dinâmicas co/existentes, heterogeneidades, multiplicidades, tensionamentos distribuídos em rede, acontecimentos imprevisíveis, vizinhanças, misturas, composições, contaminações. Há uma cidade que acontece entre as divisões que a separam. Conexões de identificações, agrupamentos de interesses, segue formigando, destrói e re/constrói, perde e re/encontra. Se desterritorializada, traça para si um novo território, faz a vez da reterritorialização que desemboca "sobre um ser, sobre um objeto, sobre um livro, sobre um aparelho ou sistema" (DELEUZE; GUATTARI, 1997, p. 224). Os corpos se dividem e dividem a cidade, criam o "seio do qual um sujeito se sente 'em casa'" (GUATARRI; ROLNIK, 1999, p. 323).

Sentir-se em casa, construir lugares. O território está ligado a um lado de fora, um exterior que penetra, desatina os sentidos e que adquire "nesse momento um valor de propriedade" (DELEUZE; GUATTARI, 1997, p. 218). Para Deleuze, criar um território "é quase o nascimento da arte" (DELEUZE, 1989, p. 3 ).

Se, para Deleuze e Guatarri (1997), a formação do território acontece na decodificação de fragmentos captados nas articulações dos meios (conteúdo e expressão), para Rancière (2005, p. 16), a arte faz parte de um regime estético-político, sendo estética "o sistema das formas a priori determinando o que se dá a sentir". Estaríamos, 
Gestos imperceptíveis: cidades em (des)ocupações... (des)territorializações...

assim, junto à expressão? E a política, ainda segundo o filósofo francês, como "o que se vê e do que se pode dizer sobre o que é visto" (RANCIÈRE, 2005, p. 17), o conteúdo?

Rancière, em uma releitura da análise kantiana do sublime, diz que a arte é "um testemunho do encontro com o irrepresentável que desconcerta todo o pensamento" (RANCIÈRE, 2005, p. 12). Arte, que fissura o pensar, estende uma linha de fuga e se abre em singularizações, "modos de sensibilidade, modos de relação com o outro, modos de produção, modos de criatividade que produzam uma subjetividade singular" (GUATARRI; RONILK, 1999, p. 17).

Por essas linhas, os desdobramentos entre artes, tensões e (des)territorializações se querem intermináveis. As possibilidades de territórios outros se fazem singulares. "As artes nunca emprestam às manobras de dominação ou de emancipação mais do que lhes podem emprestar, ou seja, muito simplesmente, o que têm em comum com elas" (RANCIÈRE, 2005, p. 26). Agitações entre autonomia e subversão que vão de uma para outra e inversamente.

Linhas, fragmentos até que em 2015, Milena Rodrigues ${ }^{7}$, amiga e professora da educação básica do distrito de Feira de Santana, Bonfim da Feira, propôs a alguns artistas visuais feirenses e soteropolitanos que se arremessassem num acontecimento artístico: colorir e provocar experiências entre pessoas e lugar no distrito de Bonfim. Artes e tensões agitam articulações, possibilidades de desterritorialização $\mathrm{e}(\mathrm{m})$ outras subjetivações? Aceitando o convite, nos dirigimos ao distrito cheios de bagagem: tintas, câmeras fotográficas, imaginações e desejos.

O distrito de Bonfim não foi mapeado pelo Google Street View. O mapa não possibilita fotos em $360^{\circ}$ e sua visualidade, nessa ferramenta, é o conjunto de telhados cortados por caminhos que entram e saem, por aqui e por ali, seis rotas que desembocam em rodovias, rodeado mais por terra que por casas. Esse distrito foi recentemente titulado “Território Quilombola” pelo INCRA (Instituto Nacional de Colonização e Reforma Agrária $)^{8}$, territórios definidos como pertencentes a "grupos étnicos - predominantemente constituídos pela população negra rural ou

7. Milena Rodrigues é pedagoga e mestre em Educação pela Universidade Estadual de Feira de Santana, artista visual e professora integral da educação básica no distrito de Bonfim de Feira desde 2010.

8. O INCRA é uma autarquia federal da Administração Pública Brasileira. Foi criada em 1970 com a missão de realizar a reforma agrária, manter o cadastro nacional de imóveis rurais e administrar as terras públicas. Informações retiradas do site www.incra.gov.br. Os quilombos eram formados por negros que fugiam da escravidão. A titulação de Bonfim enquanto "território quilombola” é importante neste trabalho por dois motivos: primeiro para marcar a relação do lugar com a cultura africana, segundo para evidenciar como o Estado institucionaliza as divisões territoriais. 
urbana -, que se autodefinem a partir das relações específicas com a terra, o parentesco, o território, a ancestralidade, as tradições e práticas culturais próprias”. Um "lugar do interior", uma "roça", um lugar rural, cheio de lentidão, campos de mato verdejante, lagos de água transbordante, gente lotada de simplicidade, atravessados por africanidades. A partir dessa descrição já tínhamos em nossa imaginação o "lugar".

Percorremos o trajeto de ônibus e, durante a viagem, outros sentidos são ocupados: as pessoas falam do prefeito, da escola, da missa de São Roque, da festa de Omulú. Um smartphone toca forró, uma menina canta, a chuva fina de agosto bate no vidro da janela, acinzenta o céu, cheiro de terra molhada, molha os pés, mela as mãos, enche os olhos, todo o corpo é tomado pelo caminho de Bonfim. A janela do ônibus já não se sabe janela ou quadro. Es-quadro? En-quadro? Tem cor e está vivo. Res-piro.

Se o trajeto é canção, a chegada é sinfonia. Sons, cores, sabores, "pastel sem miséria", o salão de dona Costinha, cavalos, risos. As conexões começam a se formar à medida que vamos entrando no lugar, conhecendo o território. Conversas sobre fé, escola, moda, história da cidade, cores preferidas, programas de TV, redes sociais. Sentimos que a fé acompanha a rotina da cidade em quase todos os seus aspectos. A igreja católica fica na praça. Depois de rezar a missa, partem para o samba. Não há sagrado ou profano, são todos sagrados! O que mudam são os ritos, as passagens, a maneira que se agrada e adora.

Em um lugar onde o tempo passa lento, uma acelaração se aproxima e acumula pessoas. Crianças chegam, pessoas enconstam, perguntam: o que está acontecendo? Um alisamento do espaço lento e o que se espera é que deslizem, fujam para outros territórios, encontrem as significâncias que façam valer seu lugar perdido.

Emicida disse uma vez que "arte é fazer parte" ças de Bonfim para compor desenhos. Cheiros, texturas, cores, agitação dos sentidos, "circulação de intensidades que empurra a desterritorialização cada vez mais longe” (DELEUZE; GUATARRI, 1995, p. 19).

Arte que desafia, "um testemunho contra a arrogância” (RANCIÈRE, 2005, p. 12), arte que contraria a tentativa de subversão do pensamento em dominar o que

9. Nome que o grupo deu ao pastel vendido no Bar/Restaurante/Pizzaria/Sorveteria de Jajai, que transbordava de recheio, qualquer que fosse a escolha.

10. Trechos retirados da música Mufete, lançada em 2015 pelo Emicida. Inspirado por uma viagem a Angola e Cabo Verde, Emicida faz relações entre África e Brasil, evidenciando as africanidades e uma cultura dominante que a tenta subverter, ao longo da história. 
Gestos imperceptíveis: cidades em (des)ocupações... (des)territorializações...

n
on
$\frac{1}{1}$

se vê, o que se pode dizer e o que se dá a sentir. Outro trecho da música Mufete, do Emicida, canta em poesia, "somos reis e rainhas, somos mesmo entre leis mesquinhas, vamos".
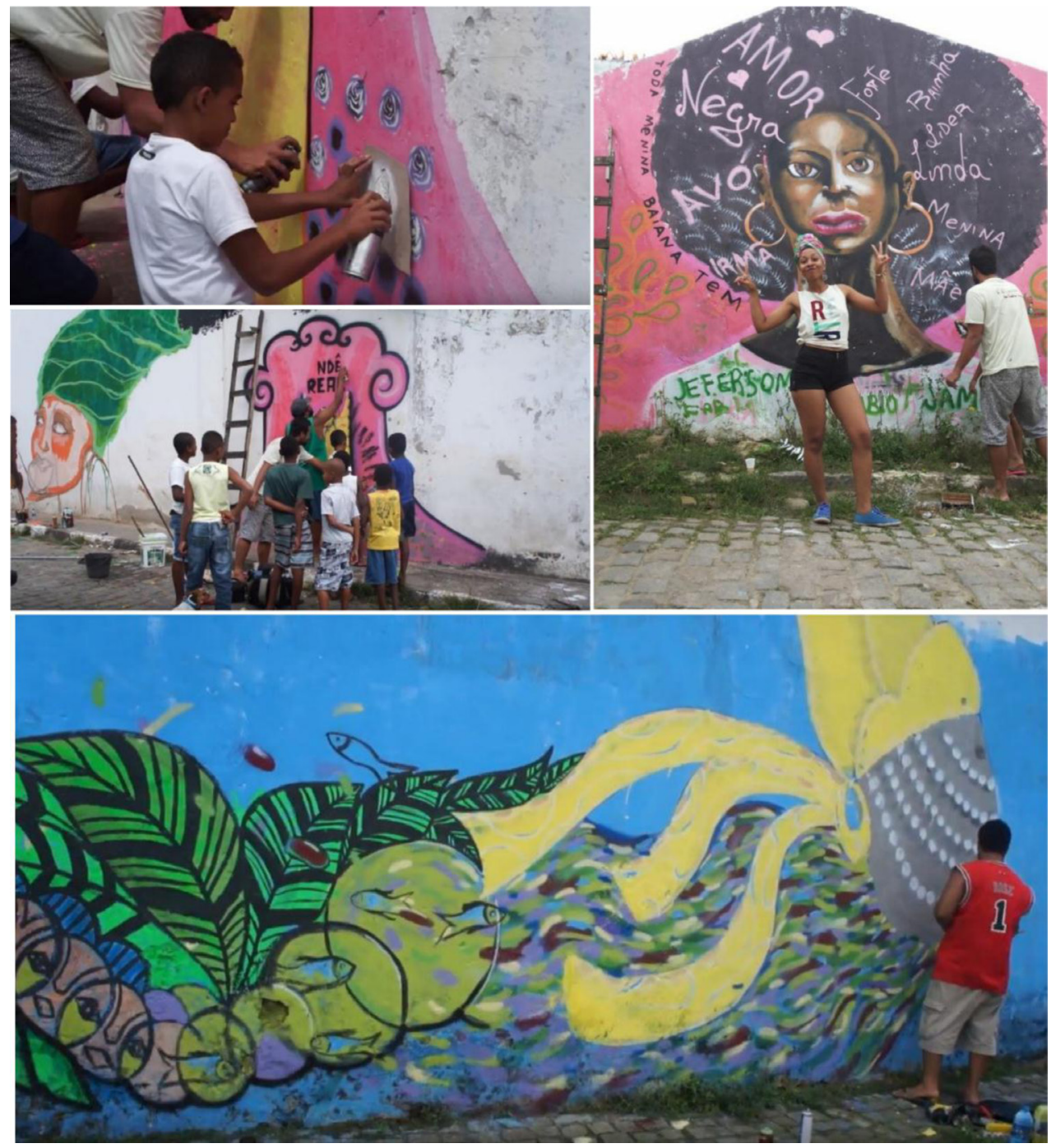

Figura 1 - Intervenção artística em Bonfim de Feira, Feira de Santana, BA. Arquivo pessoal. 
Um outro espelho se faz, outras cores e enfeites, outro olhar de deleite, outro lugar de habitação e invasão e (des)territorialização. Paredes-espelhos a cavoucarem lugares outros. Arrastam a fé escondida nos cantos para os muros da cidade. Água-espelhos inundada de cores, invadem os olhos de quem passa, segue em seu caminho cavando buracos. Seria um rio? Água, água, caminho de peixe que nada, nada, se arrasta, se prolonga em brechas, em vidas.

E nos limites de um lugar que pretende ser explicado, dividido, referenciado, os artistas visuais transbordam Bonfim através de imagens que alisam a cidade, os olhares deslizam, linhas de (des)territorialização se alongam. Rachaduras, rupturas do que se vê do lugar, um aceleramento do ritmo. Arte que pergunta: que cidade te ocupa? Um caminhar interminável por paredes e ruas e calçadas e pernas e braços e pés e cabeças e passos. Que cidade é essa que passa? Formiga, embaraça, bocas, olhos, o que se vê, quem se vê, de quem é visto ou que caminha in/visível. A cidade ocupada por tudo, ocupa em todos. Fluxos da "partilha do sensível", compartilhamento intenso de sentidos, em um coletivo imenso de corpos-espelhos-águas, "o sistema de evidências sensíveis que revela, ao mesmo tempo, a existência de um comum e dos recortes que nele definem lugares e partes exclusivas" (RANCIÈRE, 2005, p. 15). Aberturas de outras visualidades, sensibilidades, territorialidades $\mathrm{e}(\mathrm{m})$ outras subjetivações.

\section{Ambedo}

Desenhar mapas seria também gravar vozes em outra geografia: dar ênfase à importância dos veículos que estamos produzindo; renovar estratégias de contaminação, construir essa autonomia de movimento. A partícula que permeia o diagrama, no alto à esquerda, é um tipo de signo verbo-visual tal como um vírus extra-artístico. O extra-disciplinar "começa fora da hierarquia $[. . .]^{\prime \prime \prime}$. Um dispositivo para ações, modelado em contato direto. Deve-se estabelecer redes de ação para além das fronteiras locais; contaminar outras pessoas, se deixar contaminar. Ricardo Basbaum, 2010

Contaminações. In-versões. Out-venções. Ar-riscar. Pequenos detalhes sensoriais. Signos a emanarem dos gestos. Gesto-corpo a-riscado. Conexões, contatos,

11. Disponível em: <http://des-bordes.net/des-bordes/brian holmes.php>. Acesso em: 07 fev. 2016. 
Gestos imperceptíveis: cidades em (des)ocupações... (des)territorializações...

contaminações em movimentos intensivos, como nos propõe Ricardo Basbaum (2006, p. 67) ao pontuar que "[p]odemos considerar que um diagrama será sempre gerado como dispositivo relacionado ao local de proximidade máxima da experiência [...]", materialização de um devir quando o espectador é capturado por uma obra/trabalho artístico em um campo de intensidades. Arriscarmo-nos com Deleuze e o funcionamento do diagrama, quando o filósofo, ao atraversar a obra de Francis Bacon, propõe que o pintor, em seus quadros, desafia a figuração e a narração. Esses aspectos são, para Deleuze (2007), efeitos que teimam em invadir os quadros (não somente os de Bacon). Esse desafio desata fios e linhas e forças - o diagrama.

Encurvar os pilares e os ditames da educação nesse (AR)riscar, esvaziá-la dessa substância Educação que quer a tudo entender, explicar, organizar, decifrar, nomear. Esvaziar para continuar nas possibilidades das dobras, fora/dentro, gesto-corpo-cor em funcionamento para que provoquem tensionamentos de sentidos de escolas/ muros/cidades/mundos. Assim como proposto por Amorim (2007), suspeitar de uma autoridade pedagógica das coisas, através da apresentação das suas possibilidades no par atual-virtual.

Para que o diagrama funcione, para que ele seja diferente de um simples esquema, é preciso que ele revele o sentido das suas singularidades. E é porque o diagrama está sempre na interface do actual e do virtual que ele pode assegurar a passagem de um a outro por uma maquinaria que é a alma do diagrama. Essa maquinaria não está lá para representar objetos, mas para produzir, no real, uma actualização das suas componentes virtuais, revelar ao mundo sensível uma face inédita do objeto. (GODINHO, 2013, p. 141).

Propor, para essa escrita/pensamento, um funcionamento a-riscado do diagrama com a intensidade dos signos, uma vez que, como nos diz Nascimento (2013, p. 67), esse conceito em Deleuze assume um caráter sensível: "somos abertos pelo signo à potência das forças ativas criadoras”. Forças que ativam o impensado, por isso subversivo, versos que explodem e espalham uma vontade de potência. (AR) riscar proliferações como nos provoca Ricardo Basbaum (2010) com sul, sur, south. Ilha? Continente? Sul sem norte? AR(t)es vitais, talvez.

Desarranjar. Desobstruir. Des-alinhar. Inspirada por tais modalidades de (des)acertos expressivos, realizamos entre 2014 e 2015, oficinas no Colégio 
Estadual Aristides Cedraz (CEACO), Ichu, no sertão baiano, com aproximadamente 20 estudantes do segundo ano do ensino médio, onde provocamo-los, com o auxílio de várias obras artísticas a eles apresentadas, a in-ventarem imagens da cidade que transgredissem a política da representação, para, então, possibilitarem a imersão em uma lógica das sensações, pulsações de lugares recortados pelo instante de um clique sob o olhar deslocado do fotógrafo (ALMEIDA, 2015). Continuando com o projeto em 2016, realizamos mais dois encontros/ oficinas com um questionamento a atravessá-las: Que Ichu (des)enquadra em $\mathrm{mim}$ ? Como fotografar tal pergunta, nos inquietavam os estudantes? Fotografem a cidade de um outro modo, intensifiquem uma Ichu que, comumente, não podemos (conseguimos?) ver ${ }^{12}$.

Linhas, cores, texturas e $(\mathrm{m})$ desenquadramentos. Reenquadramentos? Em agosto de 2016 nosso encontro/oficina contou com a participação da artista Marli Wunder com um trabalho de intensidades pelos fios. Ressonâncias pelas superfícies das fotografias em colagens, cores, texturas a emergir pensamentos atraversados. Os traços e as cores e as linhas e os tecidos nos contêm? Que contenções são essas a desviarem das explicações e representações? Pingos de chuva escorrendo pela janela, árvores altas se dobrando lentamente com o vento, espirais de creme se formando no café...

12. Após muitas fotos reveladas e conversadas, fizemos um último encontro em 2015 com a participação de Alik Wunder no qual propusemos experimentações de processos de pós-produção através de montagens, sobreposições, raspagens, recortes, colagens e produção de novas fotografias-fragmentos (WUNDER; ROMAGUERA, 2014). Imagens que não mais remetem a lugar algum, a uma representação de um real, mas a lugares e existências nas próprias imagens (ANDRADE, 2016). 
Gestos imperceptíveis: cidades em (des)ocupações... (des)territorializações...

U
on
$\frac{1}{1}$
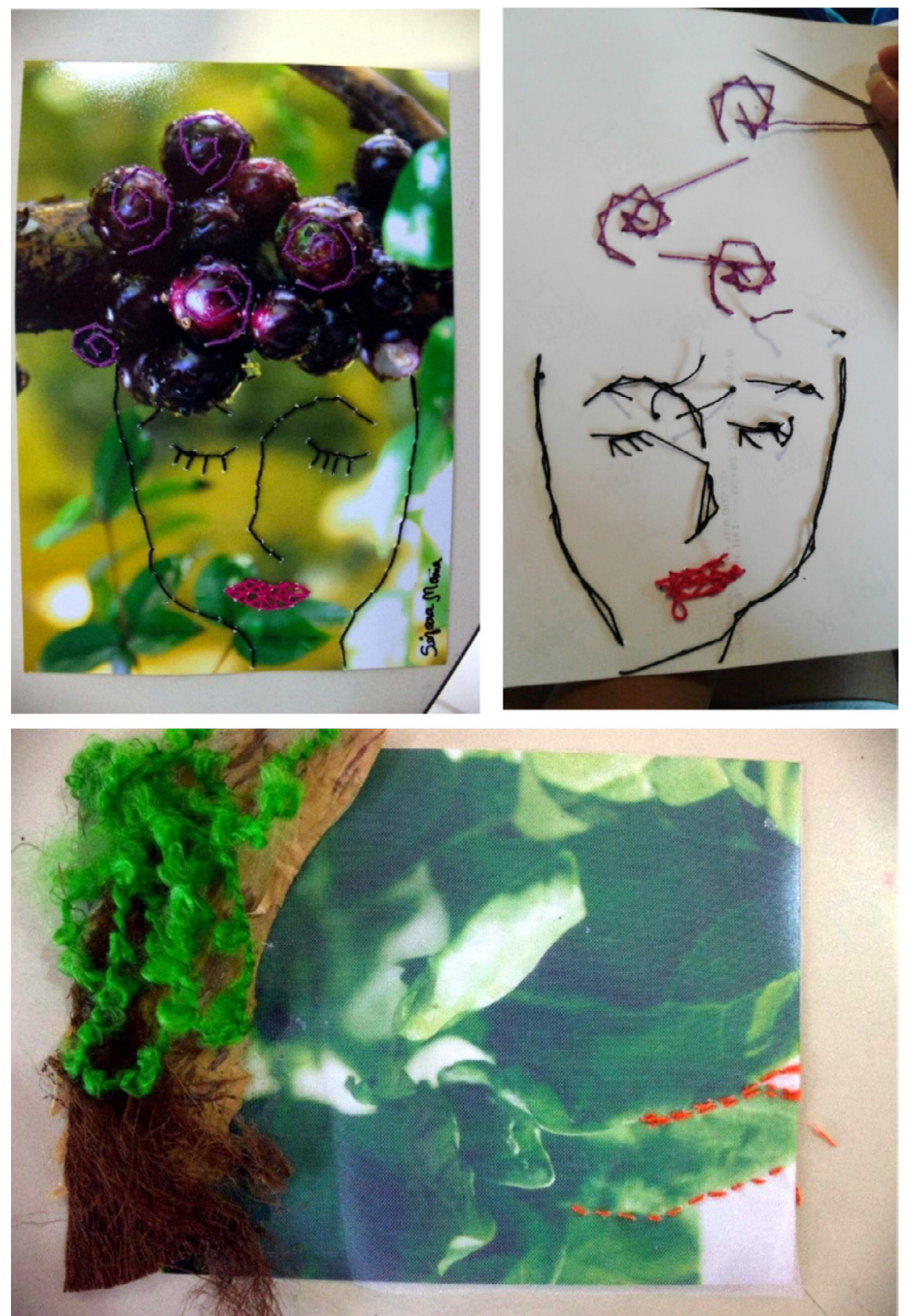

Figura 2 - Momentos da atividade com Marli Wunder. Produção dos estudantes. Arquivo pessoal. 
Jabuticaba-turbante. Linha-diagrama. Sentido-forças. Gesto-rosa. Boca-sono. Estudantes desmoronando um senso comum para as fotografias, para as superfícies que pretendem fixar um reconhecimento sobre o pensamento. Zepke (2009) ao explorar a arte contemporânea em suas tensões com os conceitos de sensação e afecção de Deleuze e Guattari nos diz que, para os autores franceses, o Minimalismo continua sua transcendência relacionada a uma certa humanidade, e para que tenhamos uma mínima condição para a criação artística é que ela crie uma sensação inumana, "[...] e como veremos, esta é também a condição mínima para um ato estético de resistência." ${ }^{13}$ (ZEPKE, 2009, p. 180). Tensionando essas discussões, nossa proposta perpassa por essa resistência caótica no traçar do fio, na perfuração de superfícies aparentemente estáveis. A potência inumana funciona como resistência aos processos de rostificação "[...] que tendem a induzir, por sua vez, a processos de classificação, massificação, padronização" (CARVALHO; FERRAÇO, 2014, p. 152).

Propostas de escape a essa injunção, entendida como uma composição segmentar dura entre significância e subjetivação (CARVALHO; FERRAÇO, 2014) em pós produção das fotografias produzidas e esvaziadas pelos estudantes durante as oficinas. Esburacar as conexões representacionais. A questão não seria apenas entrar em contato com essa movimentação no intuito de entender e desvelar os significados das imagens, mas também e sobretudo esvair-se nessas linhas de atualização no transitar dos pensamentos que ainda não foram pensados. Incomodar, desacomodar, deslocar...

Funcionar junto à textura em gestos resistentes. Atravessamentos junto a Deleuze (2007) quando tece relações e (des)conexões entre as geometrias, as sensações, as cores e as luminosidades das escolas de pintura. Em um movimento alucinante, ele nos joga (e a Bacon) em direção aos egípcios e às suas superfícies planas, à forma e ao conteúdo como dimensões igualmente próximas de um mesmo plano. Extraindo de cada época sua singularidade, Deleuze dirá então que os gregos, ao distinguirem os planos, inventando uma perspectiva, contribuíram para o que ele designa como representação clássica, que tem "como objeto o acidente, mas [...] o apreende em uma organização ótica que faz dele algo bem fundado (fenômeno) ou uma 'manifestação' da essência" (DELEUZE, 2007, p. 126, grifos do autor). Nesses atravessamentos Deleuze irrompe com esse emaranhado de pensamentos versando sobre dois planos que se cruzam: o ótico e o tátil. O movimento que quer se opor à

13. Tradução nossa. 
Gestos imperceptíveis: cidades em (des)ocupações... (des)territorializações...

representação clássica se daria então em duas direções opostas: "Ou a exposição de um espaço ótico puro, que se liberta de suas referências rumo a uma tatilidade mesmo que subordinada [...] ou, ao contrário, a imposição de um espaço manual violento que se revolta e abala a subordinação" (DELEUZE, 2007, p. 127-128, grifos do autor).

No entanto, Bacon, pintor sobre o qual Deleuze (2007) se debruça, não para nem num mundo táctil-ótico nem no mundo ótico puro. "Ao contrário, ele os atravessa, ele os subverte ou os confunde. O diagrama manual irrompe como uma zona de confusão, de limpeza, que deve desfazer ao mesmo tempo as coordenadas óticas e as conexões tácteis" (DELEUZE, 2007, p. 136). Confusão e limpeza com as quais tais imagens táteis nos brindam. Perfuração. "Estudando as audiovisualidades, tendo Gilles Deleuze como intercessor, as intensidades são o mote das linhas de aprendizado com os signos sensíveis, redescobrindo o tempo, restituindo-o no meio do tempo perdido." (AMORIM, 2013, p. 414). Instantes mínimos na linha que des-afia os contornos, desocupando-os...

Ichu-Florianópolis em outras (des)localizações. Em um encontro-oficina, em junho de 2016, quatro vídeos produzidos por professores de Florianópolis ${ }^{14}$ foram explorados pelos alunos. A ideia foi possibilitar outros movimentos com os vídeos, na paralisação dos frames. Ver o (in)visto? Que (des)enquadramentos essas inserções de tempos nos (im)possibilita? Floripas ichuenses? Ichus florianopolitanas?

14. Os pesquisadores Leandro Belinaso e Davi Codes, pesquisadores da equipe executora do projeto, da UFSC, propuseram a produção de um vídeo para professores da rede pública catarinense tensionando alguns questionamentos: A cidade nos convida a que vida? Como temos nos inventado com a cidade? Que paisagens compomos através do cotidiano que nos enreda? Como tecemos ambientes com os rastros deixados em nós pela cidade? Encontros inusitados se processam em nosso trasladar pelas ruas? Como em nosso deslocamento cotidiano o signo da cidade se desenquadra? A indicação para participar foi a de gravar um vídeo através de uma câmera qualquer a partir do deslocamento cotidiano pelo trajeto entre a casa do professor e a escola em que trabalha. O convite foi realizado através de uma carta encaminhada a quatro professores de ciências/biologia da educação básica da grande Florianópolis. Foram recebidos 4 filmes encaminhados por 3 professores. 

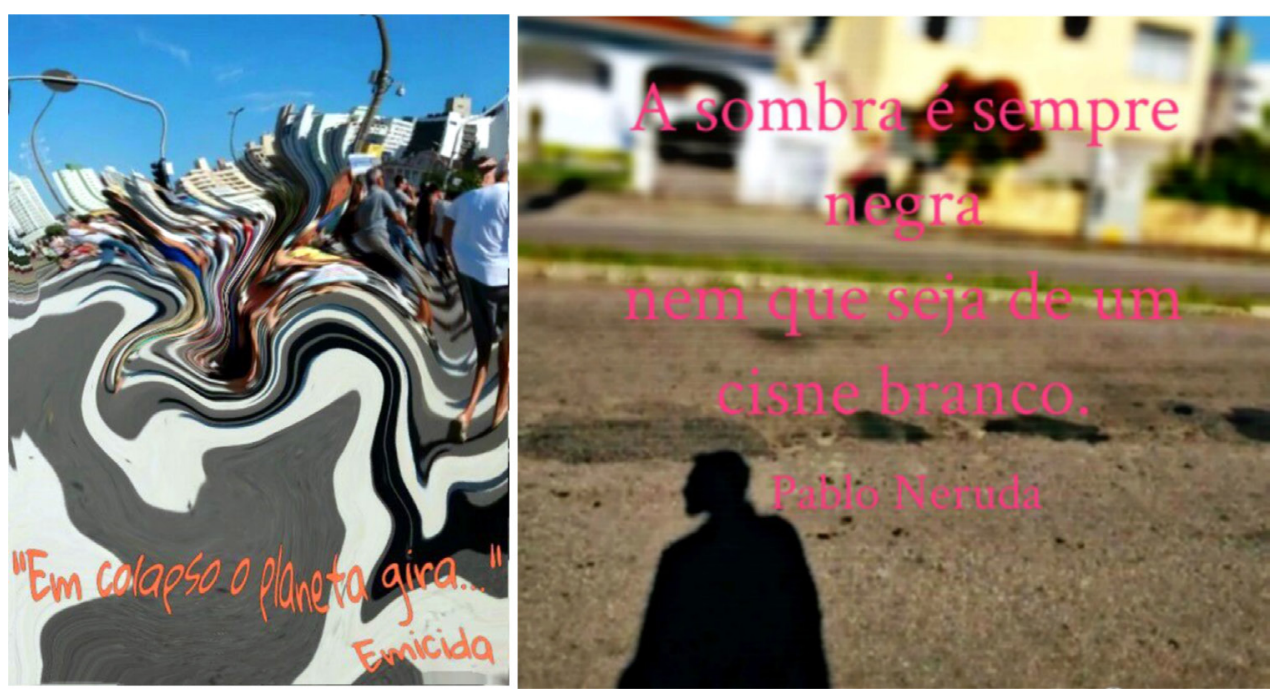

Figura 3 - Produções dos estudantes a partir de frames dos vídeos recebidos dos professores de Florianópolis. Arquivo pessoal.

Colapso, giro, liquidez e heterogenia de culturas que atravessam e versam as ruas das cidades, suas superfícies, suas expressões. Experimentação a gaguejar e criar vacúolos de comunicação pela maquinaria fixante da rostidade. Alunos, professores, jovens que per-correm as cidades e, por quais frestas festas, janelas, buracos, fendas, dobras, camadas, a espiam?

Apostamos, assim como Romaguera e Catunda (2016, p. 161) em movimentos vazantes, “[...] uma gestualidade vital do florescimento do fazer/imaginar da educação”, que, no caso dessas pesquisadoras, propõem outras maquinações para as produções audiovisuais tecidas no movimento estudantil secundarista de ocupação das escolas estaduais paulistas contra a política de redução de salas de aula.

As linhas de força são, então, de outra ordem, outra lógica, nenhum discurso já dado, mas geram muitas bifurcações divergentes e se multiplicam. Implicam na invenção de outros modos de existir e fazer escola, implicam em outra escola que se olha por dentro e pode ver aquilo que ali estava invisível. (ROMAGUERA; CATUNDA, 2016, p. 170).

Outras (des)ordens, linhas de potência em gestos imperceptíveis. Re-a-linhar o pensar a sensação para o plano educação, outros modos de existência que não a 
Gestos imperceptíveis: cidades em (des)ocupações... (des)territorializações...

exclusividade da recognição. Aposta no caos das linhas do diagrama na rua/com a rua investindo nas possibilidades táteis, visuais, de ocupação da rua. Como pensar em outras tensões com relação ao coletivo, às resistências, aos movimentos contemporâneos sem a salvação de uma humanidade perdida?

Propor, com esse funcionamento deslizante/desterritorializante, um esvaziamento dos corredores, salas de aula, giz, quadro, pincel, sinal sonoro entre as aulas, cadernos, memorizações, ruas, muros, fotografias, gentes. Chamar o susto, o imponderável, os professores, os alunos, a gestão escolar a inventar outros tempos e espaços de criação, linhas rasuradas e descentradas. Diagramar o pensarescreverpesquisar educação. Propor esse pintar sem pincel, mas com sprays das minúsculas partículas coloridas que aderem aos sulcos dos muros; esse desphotografar, já que ao riscar as fotos a luz irrompe, luz outra. Espaço hifeno e intenso de encontro entre olhos e mãos, retina e pele, tato e visão; propor, como diz Basbaum (2006, p. 88), “[...] passagens entre eles, criando territórios atravessados pelo ritmo fluido de relações, inter-relações e relacionamentos - incluindo aí forças de tração, repulsão, vizinhança, fragmentação, encadeamento, agrupamento, deslocamento, localização, etc.”. (ANDRADE, 2016, p. 664).

Revelação que não pretende estritamente uma efetuação de ação, nem opinião sobre os fenômenos, muito menos juízos de valor e de natureza, mas que se intensifica na expressão dos signos que irrompem dos gestos; que se coagula na potência do intensivo; que delira ao experimentar novas texturas sensíveis - olhos e ouvidos impossíveis. "Resiste-se e, nesse instante, conserva-se; fazem-se as marcas como uma espécie de diagrama, vê-se com um certo olho aparecer possibilidades de factos de todos os tipos" (GODINHO, 2013, p. 139), tais como: fiar com baba, larvar sem fazer nada, sentar sem dobrar as pernas, olhar para um muro de escola e não entender o que encontra, passear pelas ruas de um bairro e não distinguir as utilidades dos rabiscos. "O diagrama faz germinar. Desterritorializa e desterritorializa-se na sua potência absoluta. É um devir” (GODINHO, 2013, p. 141).

Talvez ações e $(\mathrm{m})$ gestos que, pretendemos, nos permitam algumas rupturas, em especial, com pensamentos que levem a concretizações, centralidades e determinações seja da ciência, da arte, do tempo, da produção de conhecimento ou do próprio pensamento. Rupturas que Deleuze (2003) e Deleuze; Guattari (1977) levam ao esgarçamento na intensidade da expressão maquínica, descontinuada, inorgânica na proliferação das séries de coisas, fatos, tempos, palavras. 
Queremos também deixar marcas, produzir uma marca sensível/significativa; então este desenho é principalmente um gesto, uma ação que interfere e deixa um registro, um traço. O resultado é conseguido, então, de modo a produzir um diagrama + emblema, o que leva a entender o ato de pensar como um gesto que deixa traços, produtos de marcas. (BASBAUM, 2010, n.p.).

Klexos em riscos abandonados (pontilhados?) como um trabalho de arte quase terminado, quando o quase é quase nunca. Ambedos na fragilidade absorvida por pequenos (imperceptíveis?) detalhes sensoriais. Sentidos encontrados em um Dicionário das tristezas obscuras (roteiros? Crises? Fluxos?) Sur. Bien sûr. South. Mouth. Marcas de bocas? Sul. Des-nortear-se. Sular uma (im)provável direção. Um movimento expressivo em que, talvez, pensássemos na interminável leveza do abandono da arte em uma avassaladora constatação da fragilidade e potência da vida.

\section{REFERÊNCIAS}

ALMEIDA, E. C. Que Ichu (des)enquadra em mim? Alegrar, Curitiba, PR, n. 16, n. p., 2015. Disponível em: <http://goo.gl/qkmI1Z>. Acesso em: 18 fev. 2016.

AMORIM, A. C. Três crianças a compor um plano para o currículo. Currículo sem Fronteiras, v. 13, n. 3, p. 411-426, set./dez. 2013. Disponível em: <http://www.curriculosemfronteiras.org/ voliziss3articles/amorim.pdf $>$. Acesso em: 31 mar. 2016.

. Fotografia, som e cinema como afectos e perceptos no conhecimento da escola. Teias, v. 8, n. 15-16, p. 1-12, jan./dez. 2017. Disponível em: <http://www.e-publicacoes.uerj.br/index.php/ revistateias/article/view/23998/16968>. Acesso em: 31 mar. 2016.

ANDRADE, E. C. P. Ocupações (im)prováveis: que cidade devém? ETD - Educação Temática Digital, Campinas, SP, v. 18, n. 3, p. 651-669, jul. 2016. Disponível em: <http://periodicos.sbu.unicamp. br/ojs/index.php/etd/article/view/8644678>. Acesso em: 30 ago. 2016.

BASBAUM, R. Diagramação e processos de transformação. In: CRUZ, J. (Org.). Gilles Deleuze: sentidos e expressões. Rio de Janeiro: Ciência Moderna, 2006.

. Sur, Sur, Sur, Sur... comme diagramme: carte + marque. Multitudes, França, v. o4, n. 43, p. 24-27, 2010. Disponível em: <http://goo.gl/vtMVgG>. Acesso em: 20 fev. 2016.

CARVALHO, J. M. C.; FERRAÇO, C. E. A rostidade da figura do professor e do aluno por entre os muros da escola: docência e práticas curriculares. Currículo sem Fronteiras, v. 14, n. 3, p. 143159, set./dez., 2014. Disponível em <http://www.curriculosemfronteiras.org/vol14iss3articles/ carvalho-ferraco.pdf >. Acesso em: 31 mar. 2016.

CATUNDA, M; ROMAGUERA, A. R. T. Imagens e sonoridades: é possível fissurar cotidianos escolares? Quaestio: revista de estudos em educação. v. 18, n. 1, p. 159-175, 2016. Disponível em: <http://periodicos.uniso.br/index.php/quaestio/article/view/2571>. Acesso em: 10 ago. 2016. 
Gestos imperceptíveis: cidades em (des)ocupações... (des)territorializações...

DELEUZE, G.; GUATTARI, F. Mil Platôs: Capitalismo e Esquizofrenia. Tradução de Peter Pál Pelbart e Janice Caiafa. São Paulo: 34, 1997. 5 v.

. Mil Platôs: Capitalismo e Esquizofrenia. Tradução de Aurélio Guerra Neto e Celia Pinto Costa. São Paulo: 34, 1995. 1 v.

. Kafka: por uma literatura menor. Tradução de Júlio Castañon Guimarães. Rio de Janeiro: Imago, 1977.

FERREIRA, A. B. H. Dicionário do Aurélio Online. Disponível em: <https://dicionariodoaurelio. com/>. Acesso em: 12 abr. 2017.

GODINHO, A. Diagramas para pensar/diagramas de sensação. In: GALLO, S.; NOVAES, M.; GUARIENTI, L. B. O. (Org.). Conexões: Deleuze e políticas e resistências e... Petrópolis, RJ: DP\&A; Campinas, SP: ALB; Brasília, DF: Caés, 2013.

. Máquinas anómalas e nómadas: do que ainda não existe ao que já não existe mais. Ou do que já não existe mais ao que ainda não existe. In: ROMAGUERA, Alda; AMORIM, Antonio Carlos (Org.). Conexões: Deleuze e máquinas e devires e... Rio de Janeiro: DP et Alii, 2016.

GUATARRI, F. ; ROLNIK, S. Micropolítica: cartografias do desejo. Petrópolis: Vozes, 1999.

KOENIG, J. The Dictionary of Obscure Sorrows. Disponível em: <http://www. dictionaryofobscuresorrows.com/>. Acesso em: 12 abr. 2017.

NASCIMENTO, R. D. S. Dimensões políticas da teoria deleuziana dos signos. In: GALLO, S.; NOVAES, M.; GUARIENTI, L. B. O. (Org.). Conexões: Deleuze e políticas e resistências e... Petrópolis, RJ: DP\&A; Campinas, SP: ALB; Brasília, DF: Capes, 2013.

RANCIÈRE, J. A partilha do sensivel: estética e política. Tradução de Mônica Costa Netto. São Paulo: 34, 2005.

ZEPKE, S. Deleuze, Guattari and contemporary art. In: HOLLAND, E. W.; SMITH, D.; STIVALE, C. J. (Ed.) Gilles Deleuze: image and text. London: Continuum, 2009.

WIEDEMANN, S. Duas infâncias que amavam o mar. In: ROMAGUERA, A.; AMORIM, A. C.

(Org.). Conexões: Deleuze e máquinas e devires e... Rio de Janeiro: DP et Alii, 2016.

WUNDER, A.; ROMAGUERA, A. R. T. Experimentações Coletivas por Entre Poesias, Fotografias e Ventos-Áfricas. Informática na Educação: teoria e prática, Porto Alegre, v. 17, n. 2, p. 31-45, jul./ dez. 2014.

\section{SOBRE AS AUTORAS}

Elenise Cristina Pires de Andrade é graduada em Licenciatura em Ciências Biológicas (Universidade Estadual Paulista), tem Mestrado e Doutorado em Educação (Universidade Estadual de Campinas). É professora/pesquisadora da Universidade Estadual de Feira de Santana. Tem experiência na área de estudos e escritas com imagens, filosofia da diferença, perpassando pela produção e divulgação de conhecimentos $\mathrm{e}(\mathrm{m})$ sensibilidades pelos cenários urbanos. E-mail: nisebara@gmail.com 
Louise Mara Soares Bastos é graduada em Comunicação Social (Unidade de Ensino Superior de Feira de Santana), mestranda do Programa de Pós-Graduação da Universidade Estadual de Feira de Santana, Departamento de Educação. É bolsista FAPESB.

E-mail: louiseemara@gmail.com

Recebido em 02 de janeiro de 2017 e aprovado em 04 de fevereiro de 2017. 